\title{
Las Grandes Corrientes del Pensamiento Francés
}

No cabe duda de que el tema que he escogido, algo tiene de arbitrario. El pretender reducir el pensamiento de una nación -y hasta de un hombre -a unas cuantas opiniones privilegiadas que tienen cargo de representarlas más que otras, es, evidentemente, empobrecerlo, esquematizarlo, dejarlo algo cambiado, ya que se dejan a un lado ciertos aspectos de éste. Y todo esto en nombre de unas cuantas ideas personales, y hasta puede que a causa de propias preferencias sentimentales. Pues cada cual sabe que uno siempre escoge lo que, en secreto, se le parece, y que la más benigna disertación, siempre tiene algo de confesión. Es muy probable, por consiguiente, que el mismo tema pudiera ser desarrollado de manera muy diferente. Pueden ser halladas otras constantes del pensamiento francés, que las que yo pienso señalar, puede multiplicarse su número, y también variar sus aspectos. No obstante, pienso atenerme a dos corrientes principales, que, al entremezclarse constantemente, me parece le dan al pensamiento francés, a la vez, su unidad, su complejidad, y su espíritu combativo. Es la primera la corriente crítica, a la que provisionalmente determinaré con una palabra: una corriente que en cada época se traduce por la crítica de los valores entonces al uso, y procura, con esta ocasión, plantear el problema de nuestro destino, en los términos más netos, es decir, los menos ventajosos; cualquier extranjero está más o menos enterado de esta tendencia del espíritu francés cáusticamente escéptica, o violentamente negadora: ya se sabe que los franceses son gente muy pesada que tiene la mala costumbre de volver siempre a discutir todas las cuestiones, sin darlas jamás por rematadas.

La corriente contraria es la que yo llamaré heroica. Esta es, por lo general, menos conocida, en el extranjero, y, quizás, también en Francia. Por medio de ella se expresa el atrevimiento del espíritu constructivo, que piensa, no ya en dudar o en negar, sino en afirmar, y afirmarse 
afirmando. Por lo tanto, estudiaremos primero la evolución de estas dcs amplias corrientes, que constituyen, a mi parecer, el sistema circulatorio del pensamiento francés, con su sangre roja en las arterias, y su sangre negra en las venas; concluiremos luego, procurando definirlas, lo más completa y exactamente posible.

Comenzaremos, contrariamente a lo expuesto, por la corriente heroica, pues, psicológica e históricamente, es la afirmación, anterior a la negación. Efectivamente, el primer paso que damos en el estudio del pensamiento francés nos lo muestra tirando todo al heroísmo. La literatura aristocrática, es decir, los ciclos épicos de los siglos XI y XII, y luego las novelas caballerescas de los siglos XII y XIII, nos brindan del hombre una imagen heroica, y le dan a éste modelos de heroismo que, a pesar de diferenciarse profundamente en sus cimientos, no dejan por eso de conservarse sólidamente en su forma. El ideal épico es efectivamente, como siempre, un ideal guerrero: el héroe es esencialmente un hombre de mucho valor físico, y tan completamente definido por este valor, que ni siquiera se plantea la cuestión de su valor moral. Sin miedo y sin tacha. No que este héroe se deje siempre guiar por la razón: Así en Roncesvalles, Roldán no tiene razón en negarse a tocar el cuerno para pedir auxilio a Carlos Magno (el autor no oculta su modo de ver sobre este punto). Pero en este exceso de la honra, realizã Roldán su figura de héroe. Notemos en seguida por donde este héroe de la epopeya francesa se diferencia de la época antigua. El francés (me perdonarán este juego de palabras) es esencialmente franco. Quiero decir que no cabe en él la complejidad psicológica del héroe antiguo: es Aquiles un gran señor que conoció a la corte, mientras que Roldán es un bárbaro inspirado, y tan bien inspirado que jamás ninguna civilización podrá sobrepujarlo. Su mirar es recto, obra recto y piensa recto; él no podría mirar de soslayo, ni pensar torcido. Franco, es decir siempre entero en cada uno de sus actos, de sus palabras, y hasta en sus pensamientos, enteramente a la luz, nada de sombras de trastienda. Disculpen tal insistencia: es que este carácter de "franqueza", será en lo sucesivo la característica del heroismo francés. El caballero de la epopeya sirve a su fe y a su señor; el caballero de la novela de cortesía sirve ante todo su dama. El héroe se hace caballero sirviente y luego caballero errante. Pero en el fondo, el carácter del héroe queda fundamentalmente el mismo: honra y fe; cambia el contenido de las ideas, pero no la actitud del héroe con respecto a ellas.

Ocurrirá de manera bastante curiosa - por hallarse el espíritu francés incapaz de vivir desahogado en la atmósfera céltica del misticismo amoroso, y, por un deslizamiento del misticismo amoroso al misticismo 
- religioso- que la novela de cortesía vaya a parar en la creación de un tipo nuevo de héroe: el santo. Es cosa curiosa, que la Edad Media francesa, $\tan$ atestada de historias de santos, a la que ilustra tanto celeste patrón, haya definido al santo en un personaje lego, en un caballero. Es difícil que los franceses dejemos de ver ahí la prefiguración de la que fué nuestra heroína y santa más grande: Juana de Arco.

El mencionado caballero anunciador es Galaad, el caballero rojo de la "Queste du Saint Graal". Y es tan franco también, tan hombre de Dios, que nada descubie en él esfuerzo cualquiera. Hasta tal punto, que, en su misma perfección moral, estriba su imperfección artística. Pues el sol de la gracia que lo ilumina, lo ilumina $\tan$ directo, $\tan$ a plomo, que Galaad ya ni siquiera tiene sombra; ya no tiene, como quien dice, ni cuerpo, ya no distinguimos nada, nada más que el resplandor de su armadura.

Conservemos del heroe y del santo, en su origen medioeval, este concepto de ser "brioso": un hombre que va andando en la maroma, tan cómodo, y desahogado como el paseante que va pisando la tierra más firme. Semejante, no ya a Jesús en el monte Olivete, sino a Jesús sobre las aguas del lago Tiberiades.

Este ideal de la gracia - siendo ésta la apariencia de la facilidad en la ejecución de las cosas ditíciles- lo volveremos a hallar en el concepto heroico de la "elegancia" francesa, tan permanente en nosotros, y que es: lograr con acierto tal, que nada deje descubrir nuestro esfuerza. Hay, a la vez, en esta tentativa mucho recato, caridad y orgullo.

Tengamos presente también, que, en adelante, quedan fijados los dos tipos heroicos principales franceses: el héroe y el santo.

Corneille, sin saberlo, heredó todo esto. Han hablado tanto del héroe de Corneille, que sobre él no pienso insistir. Su característica es tirar a superhombre, en el bien o el mal y lograrlo a veces. No hay entonces comuinıcación alguna entre éste y los demás personajes: si hay lucha moral (y aún es corta), y por consiguiente posibilidad de sufrir influencias en Rodrigo o en Augusto, no la hay en Horacio, Polyeucte, Cleopatra $\circ$ Nicomedes. Estos se mueven en un universo aparte, en que la voluntad tiene ademán y efectos de la gracia; ellos son intangibles, inaccesibles, y tan invulnerables como Aquiles o Siegfried, más invulnerables aún, pues ninguna parte de su piel, por más pequeña que sea, quedó olvidada, en el talón ni en la espalda. De esto resulta que el más Corneliano, quizás, entre los personajes Cornelianos, Nicomedes, atraviesa la tragedia sin obrar, sonriente entre los peligros y despreciando toda arma que no sea elegante ironía. Notemos además que uno de los héroes 
Cornelianos, Polyeucte, es un santo. Y un santo tan al modo francés, que Péguy (del que también hemos de hablar) a pesar de que sea un santo africano, que, si no fuera por Corneille, seguramente hubiera quedado desconocido, lo junta con sus santos franceses preferidos: Juana de Arco y San Luis. No cabe insistir sobre el parentesco del héroe medioeval con el héroe de Corneille: pues él justifica la palabra de los Goncourt, según la cual Corneille sería el último ejemplo de nuestra literatura aristocrática.

Efectivamente, en lo sucesivo cambia la cosa. Las almas se complican. Son más complejas, y por lo tanto más impuras. Y esto hasta la misma santidad. El pensamiento burgués, que viene a hacerse dueño del tablado, a fines del siglo XVII, trae consigo sus costumbres de crí tica, sus capacidades de análisis psicológica y sus escrúpulos de cl.גse aún mal asentada. En adelante, no tanto nace del heroismo de una cartidumbre cuanto de un drama.

Es Pascal el primero en brindarnos este nuevo concepto heroico del hombre. Al colocar en oposición la grandeza y la miseria del hombre, que son reflejo de su origen divino y de su caída, al procurar desesperadamente volver a encontrar a Dios a través de aquel velo espeso de niebla con que nos cubre nuestra humana condición, destinada, por sí misma, al pecado, Pascal funde el heroísmo con la santidad, que resulta entonces el único verdadero heroísmo, el único valedero. Es un heroísmo difícil, hecho no ya con la propia afirmación, sino con arrancamiento de sí, en que los gritos de triunfo son más escasos que los gemidos. Ya se integran el dolor y el drama, en el concepto francés del heroísmo: mucho les costará en adelante, separarse de ella.

Este heroísmo lo heredarán los románticos. Claro que algo deformado, pues ha pasado medio siglo, y mientras tanto muchas cosas han cambiado. Pero nunca se dirá bastante que, de un gran esfuerzo de renovación cristiana, fué como brotaron las primeras fuentes del romanticismo francés. El héroe se seculariza; no deja de ser pascalino el origen de su tormento, pero ya no tiene la fe. La primera nota la da Châteaubrian con René y su "mal del siglo". "El hombre es un dios caído que se acuerda del cielo" dice Lamartine. Ell tormento del héroe romántico será por lo tanto el de ser superior a su destino. Aplastado de antemano, vencido de antemano, consiste su heroísmo en luchar a pesar de todo; nace de la obstinación del desafío. Es un heroísmo negativo y negador, antípoda del heroísmo positivo que conocimos. Paralelo, de manera curiosa, de la evolución de los grandes románticos mismos, el heroísmo romántico, que nació de conceptos cristianos, tira a hacerse he- 
roísmo de revolución. Bastará para ello que los límites y obstáculos que se impongan o se opongan al héroe, condensen su agresividad en forma social. Mas, aún no ha venido el momenio; el heroísmo romántico tira a heroísmo de la revolución, pero todavía no es más que un heroísmo de rebeldía.

No, aún no ha venido el momento, puesto que en el mismo tiempo, dos generaciones de novelistas nos ofrecen otro tipo de héroe, bastante diferente. Por jalones podemos poner, si ustedes quieren, los nombres siguientes: en Stendhul, Julien Sorel, héroe de "Le rouge et le noir", en Balzac, Lucien de Rastignac, héroe en particular de "Le père Goriot", en Zola, Saccard, héroe de "Argent". Lo que caracteriza a estos héroes, es el ansia suya de potencia; individualistas encarnizados, se plantan ante la sociedad, no para negarla, sino para conquistarla; cualquiera sea el medio. Es el primer heroísmo que no sea ejemplar, quiero decir, que no sea ofrecido como ejemplo. Por cierto que Balzac y Zola condenan moralmente a sus héroes, pero no menos cierto que éstos les agradan por su vitalidad, su dinamismo, su afán de conquista. Este heroísmo, al que llamaré imperialista, es el reflejo, en el pensamiento francés, del importante desarrollo de la burguesía francesa de 1830 al novecientos.

Estos dos heroísmos del siglo XIX, parece que van en sentido contrario: el romántico desafía a la sociedad contra la que se destroza, el imperialista utiliza a la sociedad para dominarla. Pero ¿quién no se dará cuenta de que a ambos los caracteriza el individualismo más encarnizado? Lo mismo uno como otro planta al individuo frente a la sociedad, lo mismo lo exalta a expensas de la sodiedad. Demuestran que participan de la intensa llama del individualismo burgués, manera de pensar incomprensible para el heroísmo caballeresco y corneliano, lo mismo que para el heroísmo pascalino.

Precisamente a fines del pasado siglo y a principios del presente, el mundo francés intenta un retorno hacia estos últimos. El nombre principal es ahora Charles Péguy, que murió heroicamente en la batalla del Marne en 1914. Lo que basta para decir que Péguy, no sólo pensó su vida, sino que también vivió su pensamiento. Por su amor a la Revolución Francesa (en esto lo precedió y ayudó su venerable antepasado Víctor Hugo, que, por ciertos puntos lo prefigura), por su amor al heroísmo de Juana de Arco, por su amor a la santidad de santa Juana, de San Luis y de San Polyeucte, nos devuelve admirablemente nuestro antiguo heroísmo aristocrático francés, con todas sus particularidades: franco, luminoso, neto y recto. El milagro, es que ha conseguido integrarle los tormentos que ignoraran nuestros abuelos, y la fuerza explosiva de un es- 
píritu propenso a rebelarse. El héroe francés se torna en un ser atormentado por su destino, pero que sobrepuja al tormento por medio de la fe y la esperanza; que mira hacia adelante, bien derecho a su patria y a la humanidad; que mira de frente hasta a su mismo Dios ,ante el cual no teme conservar alzada la mirada, listo para combatir hasta el último aliento, para su ideal, y listo también para pelear por lo que él ama, si no está de acuerdo en cualquier punto. Fiel por cierto, pero libre, y nunca idólatra.

Después de él, otra vez, un Brasillac'h se volverá hacia Corneille, un Malraux hacia Pascal. Pero a ellos se agrega ahora una influencia extranjera; la de Nietzsche. Héroes que, careciendo de fe cristiana, se hallan no ante Dios, sino, como los románticos, ante la sociedad, estos pensadores de antes del 39 procuran, por diferentes que sean sus doctrinas, encontrar el empleo y la forma de su heroísmo, en una participación efectiva en los esfuerzos colectivos por la creación de un mundo nuevo. Heroísmo al que a menudo persigue la pesadilla de la duda y del tormento, pero de anhelos claramente revolucionarios.

En resumen, la historia del heroísmo francés nos muestra más o menos, 4 formas de este heroísmo: el heroísmo aristocrático (con la edad media, Corneille y Péguy), el heroísmo cristiano pascalino, el heroísmo burgués (romántico e imperialista), y finalmente, la tentativa para alcanzar a un heroísmo revolucionario:

Paralelamente con esta corriente heroica se desarrolla una corriente crítica. Así como el pensamiento heroico presenta, en sus principios un carácter de clase, y es pensamiento aristocrático, así el pensamiento crítico de la edad media pertenece en propio a la burguesía. Habiéndose hecho rápidamente rica y poderosa, sin haberse apartado todavía del pueblo, se expresa la burguesía de la edad media, por medio de los "fabliaux" y del "Roman de Renart". No existe aún oposición marcada, por no haber crítica razonada de los valores heroicos, y por no haberse construído la burguesía ninguna escala de valores. La única arma es la risa, nacida de la parodia (que no de la sátira), de la epopeya y la novela de cortesía. Se mofan de los valores heroicos, sin atacarlos para más. Se admiran de la astucia de Renart que le permite vencer a los fuertes, y no tratan de hacer de él un ejemplo.

El primer ataque serio que lanza la burguesía contra los valores heroicos, es la segunda parte del "Roman de la Rose", obra de un burgués erudito: Jean de Meung. Es interesante ver como se efectúa este ataque con la ayuda de esta arma potente que llaman naturalismo, un naturalismo más que medio lucreciano, en Jean de Meung. No tienen funda- 
mento natural la monarquía ni la nobleza. No se perderá este llamamiento a la naturaleza, pues casi siempre será el arma preferida de la crítica burguesa. Rabelais la toma por su cuenta, en el principio del siglo XVI.

Pero la primera obra grande del pensamiento crítico francés es, por cierto y ante todo, "los ensayos" de Montaigne. Más o menos todos los sistemas están examinados en éstos. Montaigne se respalda en toda clase de ejemplos, sacados de la historia, de la literatura antigua, y de la experiencia contemporánea. Todo pasa por el tamiz de su crítica: y ¿qué es lo que sale de ahí? La duda. ¿"Qué sé yo"?, es lo que a todo contesta Montaigne. Por todas partes va más allá de la crítica del heroísmo, y plantea el problema del escepticismo total. En cuanto al heroísmo no es más que un engaño, y Montaigne se declara decidido a ponerse a salvo de los golpes: "aunque fuera bajo el pellejo de un ternero". Cómo puede uno dar por cierto un valor cualquiera, y comprometerse para este valor, ya que no existe certidumbre absoluta alguna. La única sabiduría es un escepticismo sonriente y conciliante. Ya está soltada la palabra: Si el pensamiento heroico está en busca del héroe y del santo, el pensamiento crítico está en busca del sabio. Esos obran y éste contempla. Lo mismo que por la acción, puede lograrse el hombre por el pensamiento. Esta es la lección importante del pensamiento crítico francés desde Montaigne.

Semejante esfuerzo no volverán a hacerlo tan pronto. A principios del siglo XVII, el pensamiento crítico francés, expresado por los que llaman "Burlescos" y que ya lleva matices indudables de libre pensamiento, vuelve a utilizar los procedimientos medioevales de la parodia para combatir, no al heroísmo corneliano, demasiado elevado, sino al heroísmo novelesco del que se inspira en gran parte. Sorel, Scarron, y Furetière son los artesanos más conocidos de esta labor de destrucción. A pesar de todo, los golpes más fuertes no serán dados por ellos, sino por los moralistas del fin del siglo, La Fontaine, La Bruyère, y en cierta medida Molière, burgueses los tres por el espíritu, y el más temible de todos, La Rochefoucault, aristócrata desengañado, que pasó al enemigo Átaca éste al concepto de la virtud, sabiendo que alcanza al principio mismo del heroísmo; y concliye: no hay virtud, no hay sino disfraces del amor propio. El interés corrompe a raíz todos nuestros actos. Mientras que La Fontaine y Molière, más suaves pero no menos peligrosos, ofrecen una moral' muchio más humilde, y no vacilan, como lo hizo anteriormente Rabelais, en señalar maldad donde antes veían proezas, y cordura donde antes cobardía. Por su parte La Bruyère concluye melancólica- 
mente: "Corneille pinta a los hombres como debían de ser, y Racine los pinta como son ". Como debían de ser, pues el heroísmo no pertenece a este mundo. El balance positivo del siglo lo presentan La Fontaine y Molière, con la solución esperada: "seguid a la naturaleza, y contentaos con una cordura sencilla y tolerante".

Pero el golpe mayor lo darán en el siglo XVIII, los filósofos y sobre todo Voltaire. Es Voltaire el más inspirado destructor de valores. El hombre está hecho para ser sobrepujado, dice Nietzsche; el hombre está hecho para ser rebajado, por creerse demasiado, dice Voltaire. ¿Crees que estás hecho semejante a Dios? Pero mírate mejor y ya te darás cuenta. Te crees fénix del universo, y no eres más que diminuta parcela. Tú te crees que la Providencia no tiene más que atender a tu estimable persona: pero contempla con imparcialidad el orden del mundo, y te darás cuenta que no hay nada de eso. Los héroes son unos fanálicos: quieren imponer su concepto a los demás, pero eso es olvidarse de la poca certidumbre que tienen, y desconocer el derecho a la libertad que cada ser posee en la tierra. Los santos son unos fanáticos: con el pretexto de que la razón no es más que una luz débil, la apagan; y luego dicen que ya ven más claro. No hay sitio, en el mundo éste, para unos individuos, tan seguros de sí mismos, que pretendan imponer sus certidumbres, ni aún poseerlas. Nada más hay sitio para los cuerdos, que saben lo poco que pueden, pero no renuncian a este poco, y que no piensan en conquistarse 0 en convertirse, sino en convencerse en libre discusión, en la que ante todo importa la rectitud y prudencia del pensamiento. Y después de todo, es posible que haya varias sabidurías, y es la más alta el admitirlas a todas. Lenta, pero certeramente, el progreso de las ciencias nos va conduciendo a más luz.

¿Qué será de la crítica burguesa en el siglo XIX, en el que se señala el arranque y desarrollo de la burguesía? ¿Desaparecerá? Creerlo así, sería desconocer la virulencia de esta tendencia harto francesa y la autogeneración de las formas del pensamiento. El heroísmo romántico será criticado duramente por Flaubert. "Madame Bovary", que es como el "don Quijote" o el "Pastor Extravagante" del romanticismo, tira la primera piedra. Y a ésta seguirán otras muchas. Y la última: "Bouvard et Pécuchet", ya no es piedra sino peldaño. Pues, al contrario de sus antecesores, Flaubert es incapaz de ironizar. De todo ha de tratar seria y pesadamente. Se agarra a este heroísmo, al que aborrece, hasta amarlo, hasta no poderse privar del hastío que le inspira. "Bouvard et Pécuchet" es una como suma de todas las variedades de los idealismos contemporáneos; y la actitud conquistadora de los dos burgueses a los que saca al tabla- 
do no puede dejar de recordar a lo que yo llamé el heroísmo imperialista. Usted se cree que es Rastignac, parece que dice Flaubert, pero mírese mejor: usted no es más que Bouvard. Así Flaubert era espíritu únicamente crítico, en materia de pensamiento, y no traía novedades positivas, más que en el dominio del arte.

Cuanto cargado y de fondo desesperado fuera Flaubert, tanto sutil y sonriente es, a fines del siglo, Anatole France: que es el voltairiano más genuino del siglo XIX. No es tan encarnizado y potente como Voltaire, es menor la amplitud de su espíritu, pero es como él rebosante de ironía; y lo que hace, es menos criticar a un heroísmo determinado, cuan alcanzar la raíz de todo heroísmo, por una revisión total de nuestra condición humana. Manifiesta su escepticismo con respecto a los valores, hasta en sus nuevas formas: así por ejemplo, la historia. Y otra vez aparece la solución humana del espíritu crítico: procura ser un sabio que no se tome demasiado en serio, que considere a todas las cosas con diletantismo, y que sepa gozar de la hermosura. El dominio de Anatole France es el "Jardín de Epicuro".

Esto es, hasta ahora, el fin del gran pensamiento crítico. No es que haya desaparecido en nuestra época, pero el único nombre de prestigio con que cuenta, Gide, lleva unos rumbos tan nuevos, que no está exactamente vinculado con aquella gran tradición. Pues no es que Gide crea imposible toda certidumbre, pero considera más conveniente no escojer a ninguna y ensayarlas todas: epicurismo (revisado y corregido por Nietzsche), cristianismo, inmoralismo. No tiene para presentarnos ninguna obra grande a la que impregna el espíritu crítico, sino una sucesión de obras dogmáticas y contradictorias; no da forma a ningún sabio; más bien crearía a unos héroes que se van destruyendo uno a otro. Un discípulo de Anatole France es un espíritu sonriente que se parece a su maestro; un discípulo de Gide es, ya un espíritu que escogió a unos de los héroes fabricados por Gide, dejando a un lado los demás, ya un espíritu que se niega a pronunciarse a favor de lo que sea, por temor a ser engañado. Por primera vez, salía a luz este modo de pensar, y es preciso decir que algo de eso se debe a la importante crisis de 1914-18. Anteriormente, nuestros críticos y nuestros escépticos lo eran, si decir se puede, por convicción, en cambio, los de las entreguerras lo fueron por temor.

En resumen de esta segunda parte: se expresó el pensamiento crítico francés, ya en unos movimientos puramente negadores, y a expensas de los valores heroicos (las obras burguesas de la Edad Media, los Burlescos del siglo XVII, Flaubert), ya, por repentinas llamaradas, cuando se encarna en un espíritu suficientemente amplio, en unas obras, en 
unas obras principales que vuelven a plantear completamente, y en todos sus elementos, el problema de nuestra condición: Montaigne, Voltaire y Anatole France.

Ha llegado el momento de sacar la conclusión. Como han podido ustedes darse cuenta, procura Francia, en cada época, formarse un ideal del hombre, un tipo de hombre, que, cada vez, le parezca expresar el mejor empleo que podemos hacer de nuestras fuerzas. Pero también, $y$ por un paralelismo muy constante, hace la crítica del concepto que acaba de elaborarse. Jamás hubo en Francia un "si" que no fuera seguido por un "no". Pudiera creerse, en el principio de nuestra historia, que se trataba de un duelo entre el pensamiento aristocrático y el pensamiento burgués. Pero lo sucesivo demuestra que la realidad francesa era más compleja. Muy pronto, el pensamiento burgués heredó, con el poder, los valores heroicos que se tomó por cuenta propia, sin perder por eso la facultad de criticarse a sí misma. ¿Qué se dice? Sino que se trata de un modo de pensar genuinamente francés. Un pensamiento que constantemente se viene vigilando, al que una constante vigilancia no le impide construir, pero al que una construcción constante no le impide destruir. Un pensamiento eminentemente dialéctico, no al modo socrático en que el interlocutor no sabe sino aprobar, sino al modo francés en que éste no para de dar la contraria. ¿Quién no se va a dar cuenta de que, en este movimiento dialéctico, no sólo estriba el equilibrio francés, sino también su movimiento y su evolución?

Quedaría incompleta mi exposición de no mencionar hasta qué punto esos dos movimientos de pensamientonlejos de ser antípodas uno de otro, se compenetran y fertilizan mutuamente. Montaigne, el gran dudador, está impregnado de estoicismo, esta forma antigua del heroísmo; Pascal, el gran creador, está impregnado de Montaigne. Barrés, el gran dogmático nacionalista tiene su origen en el individualismo escéptico del que siempre le quedarán las huellas. Voltaire y Anatole France no vacilan en pelear, y en dar pecho para los valores en que ellos creen, a pesar de la amplitud de su escepticismo sonriente.

El Héroe, el Santo y el Sabio son los ideales humanos que nos hemos forjado por el curso de los siglos. Cambian sus rostros, pero su "intención", en el sentido filosófico de esta palabra, siempre el mismo, corresponde a unos tipos de espíritu bien definidos, vueltos, uno hacia la acción, y otro hacia la contemplación. Si yo le añadiese el Artista, puede que acabara de conglobar los elementos del pensamiento francés. 